\title{
Anemia management: development of a rapid- access anemia and intravenous iron service
}

This article was published in the following Dove Press journal:

Risk Management and Healthcare Policy

5 August 2013

Number of times this article has been viewed

\author{
Deepti Radia' \\ Ibrahim Momoh ${ }^{2}$ \\ Richard Dillon' \\ Yvonne Francis' \\ Laura Cameron' \\ Toni-Lee Fagg' \\ Hannah Overland' \\ Susan Robinson' \\ Claire N Harrison' \\ 'Haematology Department, Guy's \\ and St Thomas' NHS Foundation \\ Trust, London, UK; ${ }^{2}$ Bupa Home \\ Healthcare, Harlow, UK
}

\begin{abstract}
This article describes the initiation and evolution of the Rapid-Access Anemia Clinic (RAAC) at Guy's and St Thomas' Hospitals, London, UK. This clinic was set up to provide diagnosis and treatment, and to coordinate investigative procedures, where necessary, into the underlying causes of anemia. Initially piloted with anemic preoperative orthopedic patients, the clinic now treats a wide range of conditions, deriving from both internal and external referrals. Treatment includes dietary advice, supplementation with iron, vitamin $\mathrm{B}_{12}$ and folate, and blood transfusion. Most patients at the RAAC need iron replacement, the majority of which require intravenous (IV) iron. Therefore the first-line IV iron-administration protocol is carefully considered to ensure viability of the service and patient satisfaction. Four IV irons available in the UK are discussed, with explanation of the benefits and drawbacks of each product and the reasoning behind the IV iron choice at different stages of the RAAC's development. Costs to the service, affected by IV iron price and administration regimen, are considered, as well as the product's contraindications. Finally, the authors reflect on the success of the RAAC and how it has improved patients' quality-of-treatment experience, in addition to benefiting the hospital and National Health Service in achieving specific health-care mandates and directives. Drawing from the authors' experiences, recommendations are given to assist others in setting up and providing a successful rapid-access anemia service or similar facility.
\end{abstract}

Keywords: hemoglobin, iron deficiency, ferric carboxymaltose, iron sucrose, iron dextran, iron isomaltoside

\section{Introduction}

Anemia is a debilitating condition that commonly causes tiredness, lethargy, and dyspnea, and often signals more serious health problems. Compared with nonanemic individuals, anemic patients have a higher risk of mortality, hospitalization, and prolonged hospital stay. ${ }^{1-3}$ This results in higher medical costs and puts pressure on health-care services and resources. ${ }^{4}$

Anemia is often treated with iron supplementation, with or without erythropoiesisstimulating agents. But despite the efficacy of this therapeutic approach, many anemic patients do not receive appropriate treatment. ${ }^{5,6}$ While UK renal departments have wellestablished anemia clinics and treatment protocols, many other hospital departments and primary care practices do not have access to these or equivalent services. Renal anemia clinics are usually restricted to patients with chronic kidney disease, and are unable to accommodate other anemic patients due to high workloads.

In 2006, the Guy's and St Thomas' Trust (GSTT) developed the Rapid-Access Anemia Clinic (RAAC) in order to meet the needs of a variety of anemic patients (see Table 1 
Table I The variety of causes of anemia

\begin{tabular}{|c|c|}
\hline Anemia classification & Causes \\
\hline $\begin{array}{l}\text { Depressed RBC } \\
\text { production from }\end{array}$ & $\begin{array}{l}\text { - Cancers (leukemia, lymphoma or } \\
\text { secondaries) }\end{array}$ \\
\hline bone marrow & $\begin{array}{l}\text { - Bone marrow shutdown (aplastic/drugs) } \\
\text { - Anemia of chronic disease (eg, renal disease) }\end{array}$ \\
\hline Nutritional anemia & $\begin{array}{l}\text { - Iron deficiency } \\
\text { - Vitamin } \mathrm{B}_{12} \text { (pernicious anemia) } \\
\text { - Folate deficiency (megaloblastic anemia) }\end{array}$ \\
\hline Hemolytic anemia & $\begin{array}{l}\text { - Sickle-cell disease } \\
\text { - Thalassemia }\end{array}$ \\
\hline Blood loss & $\begin{array}{l}\text { - Acute (surgery, accidents) } \\
\text { - Chronic bleeding (GI bleeds, menorrhagia, } \\
\text { hematuria, epistasis) } \\
\text { - Autoimmunity } \\
\text { - Infections/fevers } \\
\text { - Drugs }\end{array}$ \\
\hline Others & $\begin{array}{l}\text { - Pseudoanemia (pregnancy) } \\
\text { - Unexplained anemia }\end{array}$ \\
\hline
\end{tabular}

Adapted from Momoh (2010), ${ }^{10}$ with permission from MA Healthcare. Abbreviations: $\mathrm{Gl}$, gastrointestinal; RBC, red blood cell.

for types/causes of anemia), and to address various healthcare improvement initiatives that were being implemented at that time, in particular the Department of Health's better blood-transfusion strategy. ${ }^{7}$ Initially, this clinic only treated preoperative anemic patients, but has since grown rapidly to include patients with a wide range of conditions. The RAAC sees approximately 50-60 patients a month referred from a variety of GSTT departments, including general hematology, gynecology, cardiology, gastrointestinal, oncology, and rheumatology. The service is also open to non-GSTT patients, referred by general practitioners or occasionally via other hospitals. Nearly all patients attending the clinic require iron supplementation, with more than $90 \%$ requiring intravenous (IV) iron. Therefore, one of the key functions of the clinic is to organize and coordinate treatment programs for patients with iron-deficiency anemia, and to administer IV iron.

This article describes the development of the GSTT RAAC. It shares key learning and experiences, and demonstrates the value of providing a dedicated anemia service, both to patients and the National Health Service (NHS). In particular, it discusses the importance of selecting the right IV iron to ensure that the clinic is not only cost-effective but is able to deliver an efficient, effective, and safe patient-centered service.

\section{Clinic design and service development}

The RAAC was piloted in anemic orthopedic patients awaiting surgery, where standard anemia treatment included the use of erythropoiesis-stimulating agents and/or supplementary iron. An initial evaluation (Figure 1) found that preoperative treatment of anemia successfully reduced the need for blood transfusion during and after surgery, and helped to prevent delay or cancellation of the surgery. With this success, and the clinical demand for an anemia-treatment service, the team of nurses and consultants involved in the pilot were in a position to develop a formal clinic: the RAAC. Mandates on improving patient experience, service quality, and efficiency also played a role in driving development. There was internal agreement to provide a service that was:

- simple: a "one-stop shop" providing diagnosis and treatment to which all GSTT consultants and doctors and general practitioners could refer their patients

- patient-centered: to ensure quality of service and compliance, with patient experience driving the service design

- investigative: to not only treat anemia, but to coordinate the investigation of the underlying cause, if not already known.

The clinic was initially developed as a nurse-led service that ran in parallel with the consultant-led general hematology clinic. The team conducted a patient-satisfaction survey to help determine whether the service could meet its key objectives. Patients rated the clinic highly, with $96 \%$ being very satisfied with the care and treatment provided, although they commented that the clinic was very busy and shortstaffed. With the loss of the clinical nurse specialist (postholder moved) and to manage staffing effectively to provide a continuous, uninterrupted service, the RAAC switched from a nurse-led service to a day-unit service. The RAAC still runs every day of the week as originally set up, but in place of a specific anemia nurse who oversaw the service and managed the nurse-led clinic, the day-unit nurses have continued to provide the service and there is a named nurse competent in vetting, assessing, and managing the patients, with a specialist trainee (registrar) based in the day unit to review, if needed, and arrange further investigations as necessary. The final review of investigations and outcomes still takes place in the anemia clinic with the consultant. A defined patient pathway (Figures 2 and 3), along with investigation and treatment protocols and diagnosis algorithms, were developed to ensure delivery of a consistent, high-quality service. Anemic patients (defined as hemoglobin $[\mathrm{Hb}]<10 \mathrm{~g} / \mathrm{dL}$ ) are seen within 1-2 weeks from referral, and receive appropriate treatment in accordance with the trust's policy and approved guidelines. Treatment options, which are supported with additional health education, include:

- dietary advice

- iron replacement (oral or IV iron) 


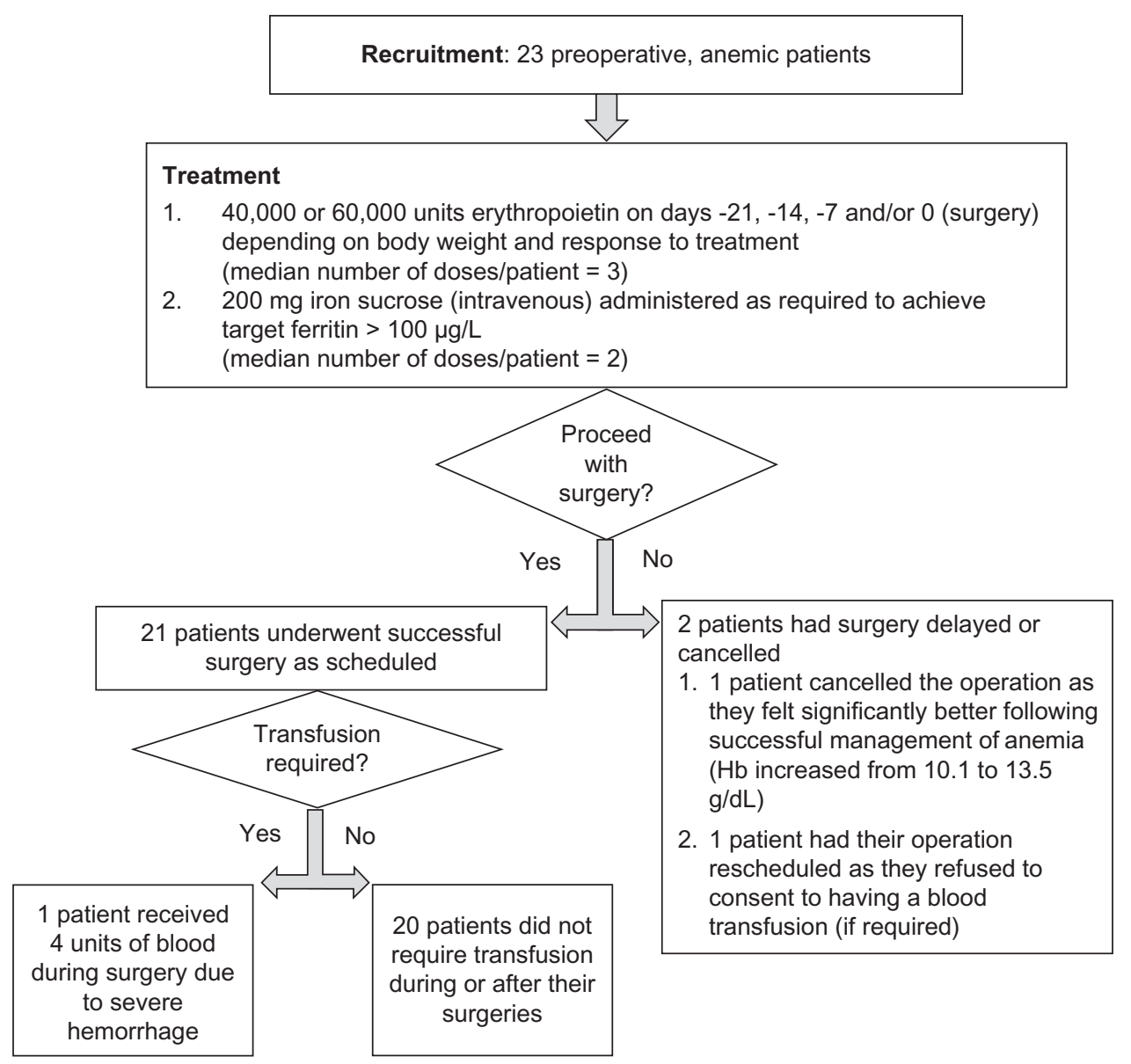

Benefits of preoperative treatment of anemia

1. Improved patient experience

2. Reduced need for blood transfusion in line with the DoH better blood transfusion strategy ${ }^{7}$

3. Enabled surgery to proceed according to schedule, helping to achieve the DoH mandate that patients should receive treatment within 18 weeks from referral ${ }^{8}$

Figure I Pilot clinic: overview and results of a trial to investigate the impact of preoperative treatment of anemic patients awaiting orthopedic surgery. ${ }^{9,10}$ Abbreviations: DoH, Department of Health; Hb, hemoglobin.

- vitamin $\mathrm{B}_{12}$ replacement

- folate supplements

- red cell/blood transfusion.

The underlying cause of anemia is unknown in approximately $40 \%$ of cases referred to the RAAC. ${ }^{10}$ In these cases, a thorough investigation is conducted to identify the cause of anemia, and subsequently the patient is referred to the appropriate specialist for further treatment. Approximately $25 \%$ of these patients had an underlying gastroenterology cause - polyps, diverticulitis, angiodysplasia, gastric ulcer, and peptic ulcer disease - and four patients harbored an occult colonic cancer. Of the remaining $15 \%$, a small proportion of patients were multiparous females with chronic iron deficiency.

\section{IV iron usage and selection}

The vast majority of patients who attend the clinic are iron-deficient and either do not tolerate or respond to oral iron therapy, and thus require IV iron. Approximately 15-16 doses of IV iron are administered per weekly clinic, with patients requiring an average of $1000 \mathrm{mg}$. Owing to the high usage of IV iron and the large number of doses administered per week, the IV iron-administration protocol affects the viability (cost and resource management) and risk governance of the overall service. Additionally, the protocol can have a large impact on patient experience, and consequently requires careful consideration in terms of design so that it is appropriate for both the service and the patient. 


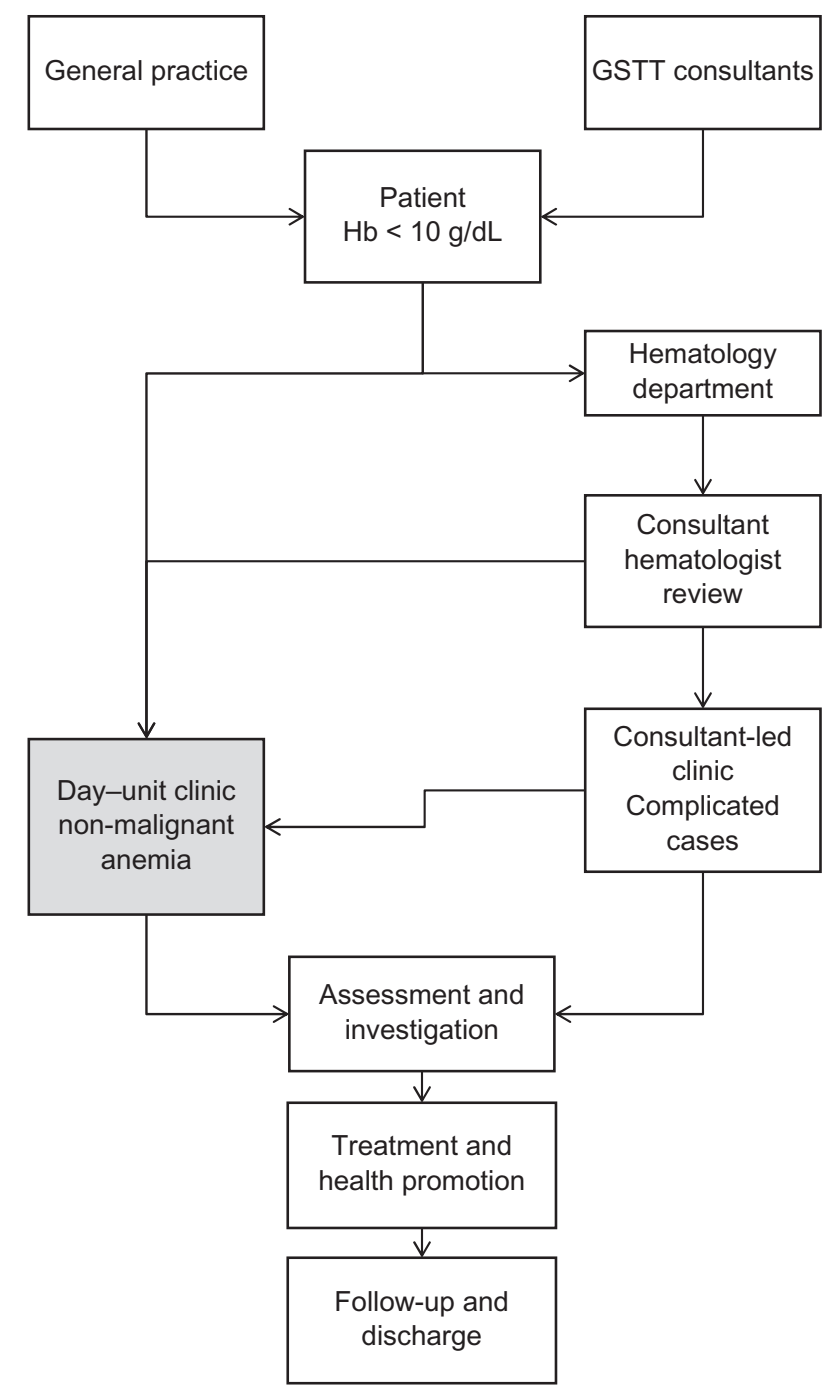

Figure 2 The patient pathway developed by the Guy's and St Thomas' Rapid-Access Anemia Clinic

Note: Adapted from Momoh (2010), ${ }^{10}$ with permission from MA Healthcare. Abbreviations: Hb, hemoglobin; GSTT, Guy's and St Thomas' NHS Foundation Trust.

Four IV irons are available in the UK: iron sucrose, low-molecular-weight iron dextran (LMWID), ferric carboxymaltose (FCM), and iron isomaltoside (Table 2). ${ }^{11-15}$ To ensure provision of an efficient, simple, and cost-effective service, the RAAC recommends specific, first-line IV iron as a primary consideration for those patients who require IV iron. As the type of IV iron used dictates the design of the IV iron protocol, the first-line IV iron requires careful selection. Cost is a clear differentiating factor between the IV irons, but it should be emphasized that these products are not clinically equivalent. The IV irons differ in their administration regimen and contraindications, which in turn affects patient experience and the viability and risk management of the service. Therefore, these factors are taken into consideration when recommending a first-line IV iron. The RAAC also regularly reviews the recommendation as new data and products become available, and as patients' needs change.

The RAAC has updated the first-line IV iron protocol several times since its original development. The initial IV iron used in the clinic was iron sucrose, because of the hospital's extensive experience of the product in the renal department for treating anemia in chronic kidney disease. Additionally, iron sucrose was already on the hospital formulary and therefore was readily available.

However, it was found quickly that using iron sucrose posed a number of challenges for the RAAC service. A maximum of $200 \mathrm{mg}$ iron sucrose can be administered in a single dose, ${ }^{12}$ but many patients referred to the RAAC required doses in excess of this upper limit. Consequently, they needed multiple appointments, commonly four to six visits, to receive their total iron dose. This was inconvenient for patients, especially elderly orthopedic patients with restricted mobility who relied upon time-consuming hospital transport to get to and from the clinic. In addition, iron sucrose treatment required administration of a test dose and close patient monitoring to check for adverse reactions. This, combined with the high number of doses that each patient needs, placed the service under significant pressure.

Following a review of the service and the availability of IV irons at the time, the GSTT RAAC switched to LMWID, which can be given as a total dose infusion up to $20 \mathrm{mg} / \mathrm{kg}$ body weight. ${ }^{13}$ This switch had a positive impact on patient experience (especially those relying on hospital transport) and on service provision, as patients needing high iron doses required only one hospital visit to receive their treatment. Furthermore, the updated service was easier to manage and enabled more patients to be seen. However, LMWID infusions still required administration of a test dose and close patient monitoring. A further challenge was that total dose infusions took 4-6 hours, thus requiring an almost whole-day appointment, which restricted the number of patients that could be treated for any condition in the busy unit per day. Added to this, the RAAC started treating more young women referred from gynecology. This patient group included more employed people needing to take a full day off work for treatment, which has a potential impact on income and a consequent increase on the economic burden of the condition. It therefore became apparent that LMWID may not be a suitable first-line choice and new options that were available needed to be considered.

At this time, two high-dose, rapid-administration IV irons became available in the UK: firstly, FCM, and more recently, iron isomaltoside. Following a favorable review 


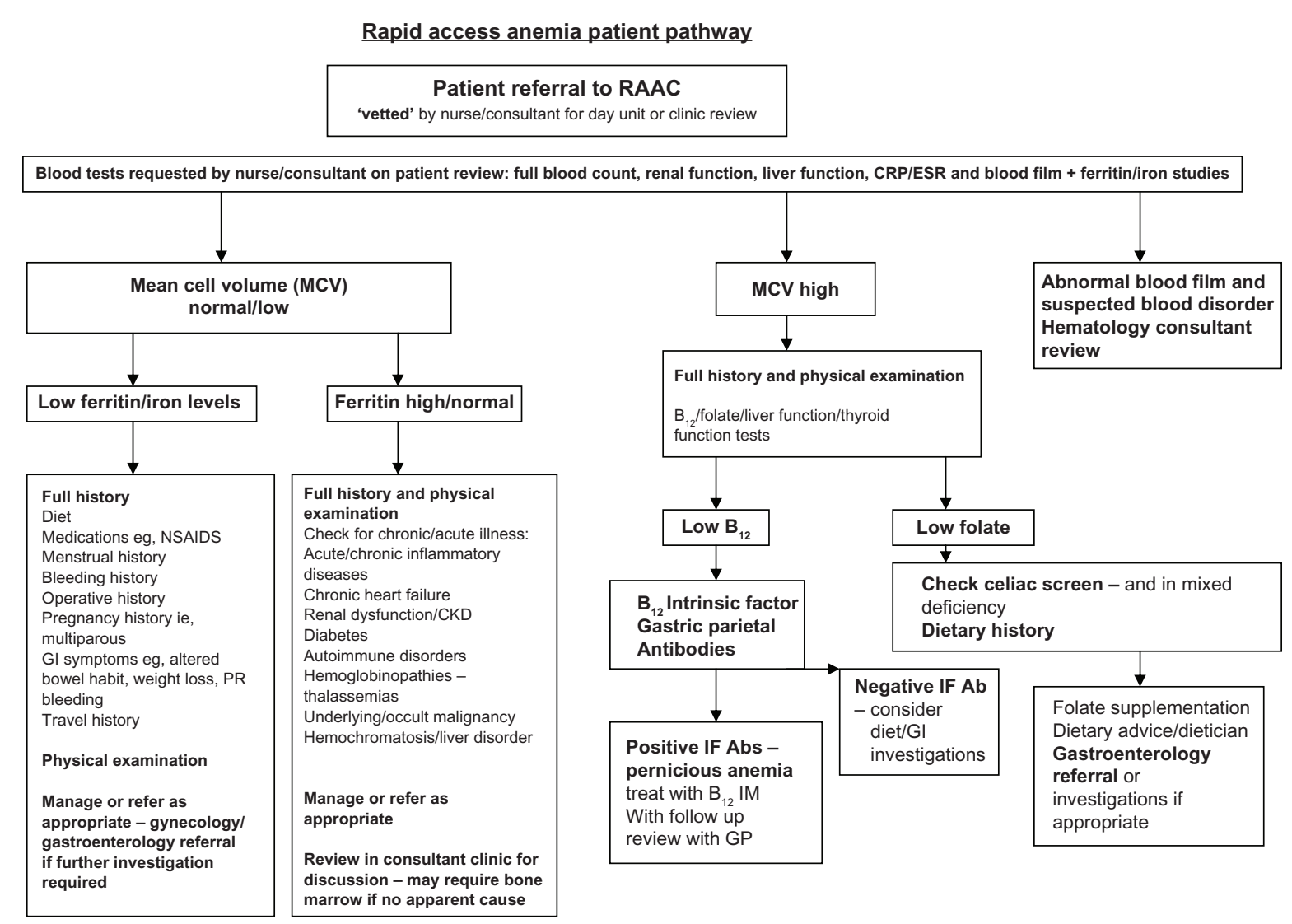

Figure 3 RAAC patient pathway.

Abbreviations: Ab, antibody; CKD, chronic kidney disease; CRP, C-reactive protein; ESR, erythrocyte sedimentation rate; GI, gastrointestinal; IF, intrinsic factor; IM, intramuscular; MCV, mean cell volume; NSAIDS, nonsteroidal anti-inflammatory drugs; PR, per rectal; RAAC, Rapid-Access Anemia Clinic.

of these products, the GSTT RAAC clinic switched from LMWID to FCM. Based on the FCM summary product of characteristics and together with internal consultation, the RAAC amended the IV iron protocol, allowing patients weighing $>50 \mathrm{~kg}$ to receive up to $1000 \mathrm{mg}$ FCM infused over 15 minutes, and patients weighing $\leq 50 \mathrm{~kg}$ to receive up to $500 \mathrm{mg}$ infused over 6 minutes. This single-dose adjustment by weight was to keep the administration process simple for the patient pathway. However, in clinical practice FCM is infused over 15-20 minutes; this slightly longer infusion time is employed, as it enables RAAC staff to multitask and simultaneously manage several patients in a very busy day clinic. This rapid administration of high doses of IV iron has substantially improved service provision and patient experience. Patients take less time off work, minimizing the social and economic burden of the disease. Furthermore, it enables more optimal use of resources (staff, beds), improves service efficiency by increasing patient throughput, and reduces the time patients spend on the RAAC waiting list. The improved service efficiency, use of resources, and increased patient throughput (with the potential to increase the service income in order to continue to support the service) makes FCM, the most expensive IV iron, a cost-effective option.

One potential drawback with the RAAC protocol for FCM, compared with LMWID, is that it has a maximum dose of $1000 \mathrm{mg}$ or $500 \mathrm{mg}$ per administration (depending on body weight). Theoretically, patients may require more than one visit to receive sufficient iron. However, in the RAAC's experience, this is only the case for 3\%-9\% of FCM patients. A pragmatic approach to iron dosing and $\mathrm{Hb}$ targets can keep patient visits to a minimum. The $\mathrm{Hb}$ target, and consequently IV iron dose, should depend on the patients' clinical situation and their starting $\mathrm{Hb}$ level: the actual $\mathrm{Hb}$ target for an individual patient may not be the "normal" $\mathrm{Hb}$ level suggested in IV iron-dosing instructions. The "normal" $\mathrm{Hb}$ level, as specified for sex and weight on the summary of product characteristics, is not a reflection of what is aimed for in clinical practice. A target of $15 \mathrm{~g} / \mathrm{dL}$ would not necessarily be aimed for in every patient, but will be tailored to meet what is needed, ie, $>12.0 \mathrm{~g} / \mathrm{dL}$ for gynecological surgery if possible, $>10 \mathrm{~g} / \mathrm{dL}$ for orthopedic surgery, and set patientfocused targets depending on their clinical condition and comorbidities. The vast majority of patients within our clinical 


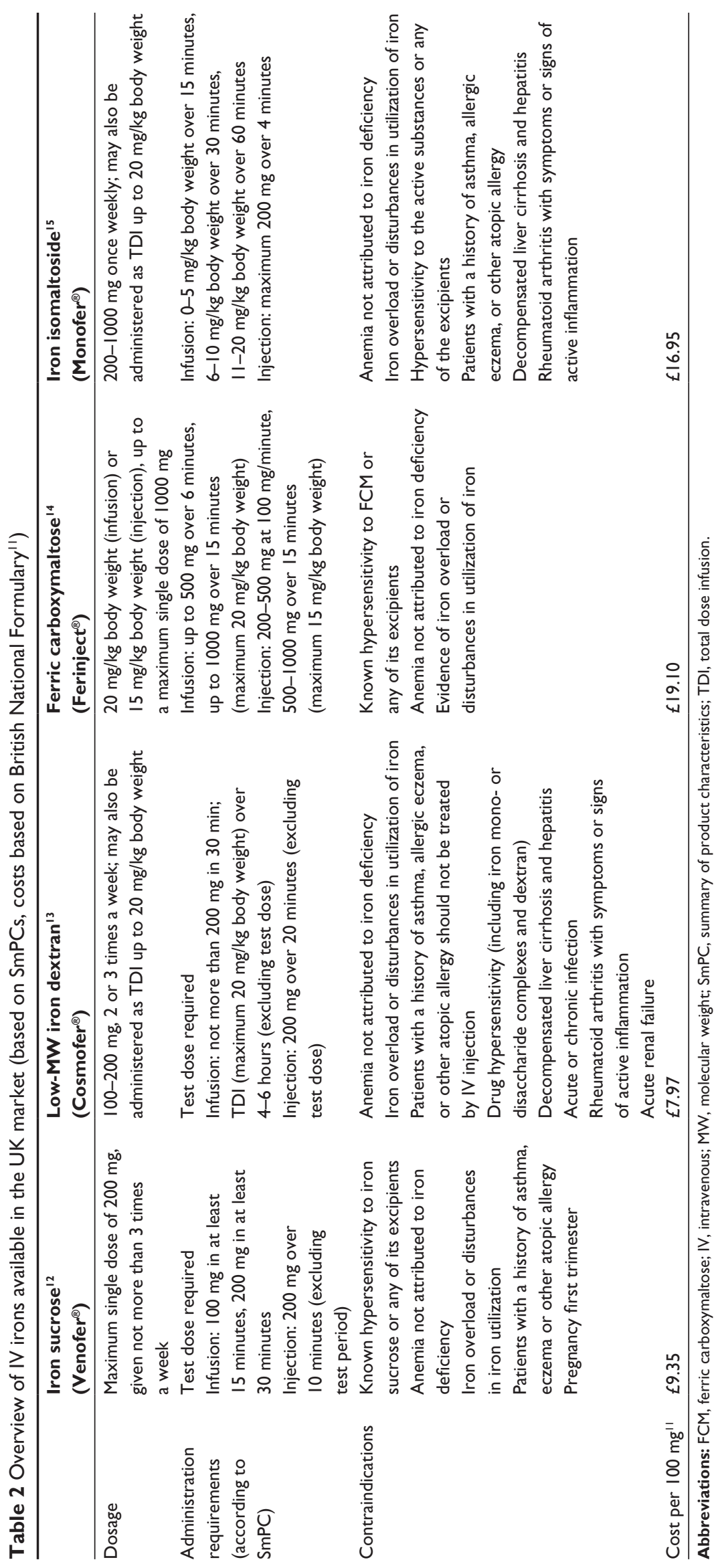


practice generally do not require doses greater than $1000 \mathrm{mg}$ to benefit from treatment and meet their individual $\mathrm{Hb}$ target, although higher iron doses $(>1000 \mathrm{mg})$ may be required to reach "normal" $\mathrm{Hb}$ targets in some patients.

Furthermore, FCM has the potential to provide greater increases in $\mathrm{Hb}$ levels with lower doses compared with LMWID. Clinical data from patients treated with FCM ( $\mathrm{n}=82$, at a dose of either $500 \mathrm{mg}$ for patients $<60 \mathrm{~kg}$ body weight or $1000 \mathrm{mg}$ for patients $>60 \mathrm{~kg}$ ) was compared with data from patients historically treated with LMWID $(n=44$, at total dose infusion of $20 \mathrm{mg} / \mathrm{kg}$ ). Data showed that at week 6, the mean increase in $\mathrm{Hb}$ from baseline was significantly greater $(P<0.01)$ with FCM $(2.7 \mathrm{~g} / \mathrm{dL})$ compared with iron dextran $(1.4 \mathrm{~g} / \mathrm{dL}) .{ }^{16} \mathrm{In}$ this pretreatment, mean $\mathrm{Hb}$ was $9.0 \mathrm{~g} / \mathrm{dL}$ (95\% confidence interval 7.2-10.7) in the FCM group and $9.7 \mathrm{~g} / \mathrm{dL}(8.3-10.9)$ in the LMWID group. Mean serum ferritin was $27 \mathrm{mcg} / \mathrm{L}$ and mean cell volume (MCV) $76 \mathrm{fL}$ in the FCM group; mean ferritin was $23 \mathrm{mcg} / \mathrm{L}$ and MCV $79 \mathrm{fL}$ in the LMWID group. At 6 weeks posttreatment, mean $\mathrm{Hb}$ was $11.7 \mathrm{~g} / \mathrm{dL}$ in the FCM group and $11.1 \mathrm{~g} / \mathrm{dL}$ in the LMWID group $(P=0.04)$. Mean ferritin was $221 \mathrm{mcg} / \mathrm{L}$ and MCV $83 \mathrm{fL}$ after FCM, and mean ferritin was $171 \mathrm{mcg} / \mathrm{L}$ and MCV $85 \mathrm{fL}$ after LMWID; these differences were not statistically significant. The mean increase in serum ferritin was $149 \mathrm{mcg} / \mathrm{L}$ in both groups, and the increase in MCV was $7 \mathrm{fL}$ with FCM and $6 \mathrm{fL}$ with LMWID; this difference was not statistically significant. Our findings do, however, need confirmation from further controlled studies, but in the reallife setting, most patients receiving FCM require only one visit to receive their IV iron.

The final IV iron that the clinic considered was iron isomaltoside, which, like FCM, can be administered rapidly at high doses. Although iron isomaltoside is less expensive than FCM, making it more attractive from a financial perspective, it is contraindicated in a greater number of patient groups (Tables 2 and 3). As the RAAC service has expanded, so has the clinical diversity of the patients. Therefore, it is critical to use an IV iron approved for use in a broad range of patients to minimize risk. As risk minimization and governance takes precedence over cost savings, FCM remains the first-line IV iron for the GSTT RAAC. Experience of IV irons used in the RAAC is summarized in Tables 3 and 4.

\section{Discussion}

The GSTT RAAC has now been in operation for 6 years. It provides patients with prompt diagnosis, treatment, and, where required, investigation into the cause of anemia. The service may improve patients' quality of life by treating their

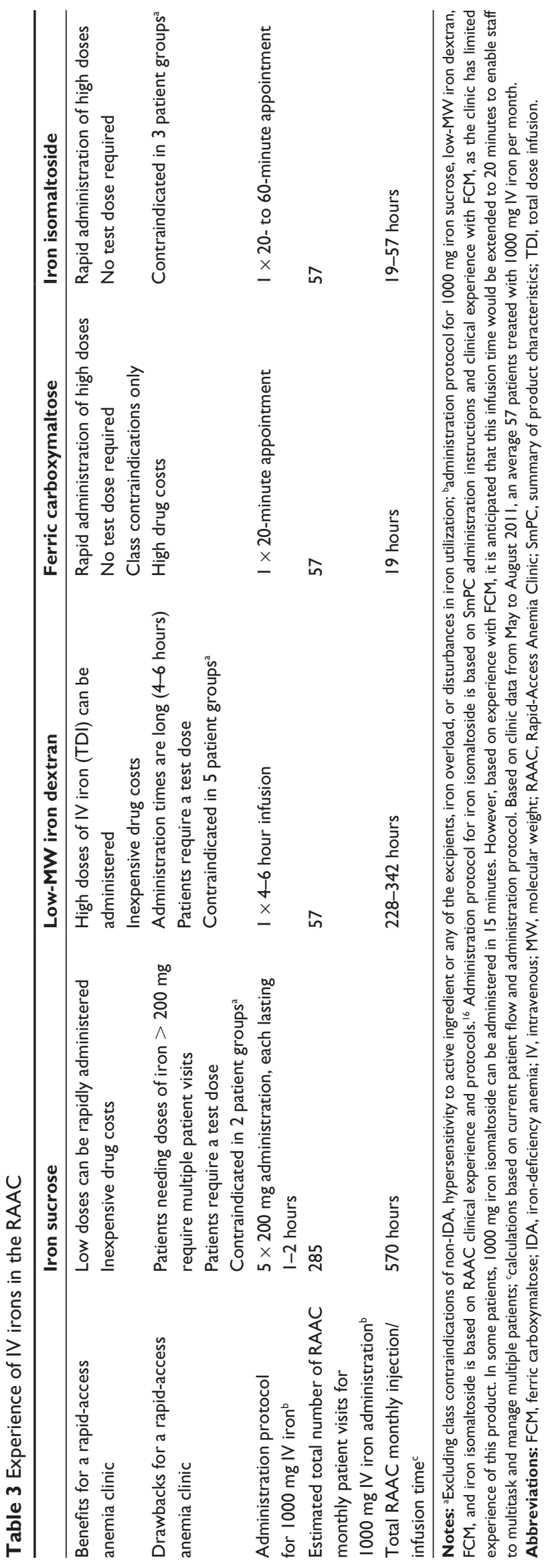


Table 4 RAAC rating of IV irons based upon influencing factors

\begin{tabular}{llll}
\hline Factor & Influencing IV iron property & IV iron rating & \\
\cline { 2 - 3 } & & Iron sucrose & Low-MW iron dextran \\
\hline Patient experience & Administration requirements & $\checkmark-\checkmark \checkmark$ & $\checkmark-\checkmark \checkmark$ \\
& & (depending on dose and & (depending on dose and \\
& & patient population) & patient population) \\
Viability (overall service & Administration requirements, & $\checkmark \checkmark$ & $\checkmark \checkmark$ \\
$\begin{array}{l}\text { cost, service income, and } \\
\text { resource management) }\end{array}$ & including drug costs & & $\checkmark \checkmark \checkmark$ \\
$\begin{array}{l}\text { Safety and risk } \\
\text { governance }\end{array}$ & Licensed indication/ & $\checkmark \checkmark$ & $\checkmark \checkmark$ \\
\hline
\end{tabular}

Notes: aIV iron rating based on assessment conducted by Guy's and St Thomas' RAAC team, from low $(\checkmark)$ to highly rated $(\checkmark \checkmark \checkmark)$.

Abbreviations: FCM, ferric carboxymaltose; IV, intravenous; MW, molecular weight; RAAC, Rapid-Access Anemia Clinic.

anemia, and supports early identification of more serious underlying conditions. An audit was carried out in 2009 regarding the patients' view of a nurse-led anemia clinic. Fifty patients responded: $97 \%$ felt the nurse listened to what they had to say; $94 \%$ said the nurse gave them enough of an opportunity to ask questions; $94 \%$ felt that the nurse answered all their questions, with $98 \%$ understanding their management plan for their anemia; and $96 \%$ felt they were involved in the decisions made about their treatment.

It has also become apparent that the service provides numerous benefits to the hospital and the NHS, as it enables better management of hospital resources and helps to achieve health-care directives/mandates (Table 5), ${ }^{7,8,17,18}$

The success of the RAAC relies on its careful and diligent management. Primarily, the service needs to be easy to access and simple to use for both the patients and the referring health-care professionals. In addition, the clinic's success depends upon the implementation of its clear diagnostic and treatment protocols. Multiple causes of anemia are identified and treated, and patients must be individually assessed to establish the best treatment option for them. For cases of anemia caused by iron deficiency, oral iron supplementation may be suitable; however, from experience, most patients referred to the clinic do require IV iron, and this form of therapy is becoming increasingly popular, as it rapidly improves patients' $\mathrm{Hb}$ and potentially their quality of life. Therefore, the IV iron-treatment protocol has a significant impact on the management of the clinic and patient experience.

To create a simple, straightforward treatment process, the IV iron protocol recommends use of a first-line product. In the RAAC's experience, it is important to consider multiple factors when choosing IV irons to use within the clinic. These include:

- patient experience: the number of patient visits and time spent receiving the IV iron

- service viability: service resources (staffing, clinic space, beds, etc) and effect on budget (determined by the service income versus the overall cost of the service)

Table 5 The RAAC helps to manage resources and achieve health-care mandates/directives

\begin{tabular}{|c|c|c|}
\hline Health-care mandate/directive & Description/objective & How RAAC helps to achieve mandate/directive \\
\hline $\begin{array}{l}\text { DoH - Tackling hospital waiting: } \\
\text { the I8-week patient pathway - an } \\
\text { implementation framework, and } \\
\text { delivery resource pack }\end{array}$ & $\begin{array}{l}\text { Patients must start directive treatment } \\
\text { within } 18 \text { weeks of GP referral }\end{array}$ & $\begin{array}{l}\text { Patients are seen within I-2 weeks of referral } \\
\text { Proactive management of anemia in preoperative patients } \\
\text { reduces the risk of procedure delays and cancellations }\end{array}$ \\
\hline $\begin{array}{l}\text { DoH - Better blood-transfusion } \\
\text { strategy: safe and appropriate use } \\
\text { of blood }^{7}\end{array}$ & $\begin{array}{l}\text { Avoid the unnecessary use of blood } \\
\text { and blood components in medical and } \\
\text { surgical practice }\end{array}$ & $\begin{array}{l}\text { Proactive anemia treatment reduces the need for blood } \\
\text { transfusion in orthopedic surgery patients } \\
\text { Prevents emergency/unnecessary transfusion in IDA }\end{array}$ \\
\hline $\begin{array}{l}\text { NHS - QIPP (Quality, Innovation, } \\
\text { Productivity, and Prevention) } \\
\text { initiative }^{17}\end{array}$ & $\begin{array}{l}\text { Strategy involving all NHS staff, patients, } \\
\text { and clinicians that aims to improve the } \\
\text { quality and delivery of NHS care while } \\
\text { reducing costs }\end{array}$ & $\begin{array}{l}\text { Promotes better planning and management of cross-disciplinary } \\
\text { NHS services, improving efficiency and health-care provision }\end{array}$ \\
\hline $\begin{array}{l}\text { NHS - Better care, better } \\
\text { value indicators } \\
18\end{array}$ & $\begin{array}{l}\text { Identifies potential areas for } \\
\text { improvement in efficiency. } \\
\text { One indicator is reducing emergency } \\
\text { admissions of ambulatory sensitive } \\
\text { care conditions }\end{array}$ & $\begin{array}{l}\text { IDA is a listed ambulatory sensitive care condition } \\
\text { Proactive management and treatment of IDA will reduce the } \\
\text { number of IDA-related emergency admissions. Any remaining } \\
\text { emergency cases are referred directly to the RAAC, instead of } \\
\text { to the accident and emergency department }\end{array}$ \\
\hline
\end{tabular}

Abbreviations: DoH, Department of Health; IDA, iron-deficiency anemia; NHS, National Health Service; RAAC, Rapid-Access Anemia Clinic. 
- safety and risk governance: the safety profile of the IV iron in terms of the clinical profile of the patient population

- ultimately, the final selection should be a balance between all of the above factors.

While the clinic uses FCM as a first-line IV iron in the majority of patients, it is important that a selection of products is kept on the formulary: there is no single IV iron that suits all patients, and consideration has to be given as to which first-line IV iron is the most suitable in terms of patient needs and management, and subsequently what provides the best use of hospital resources. In addition to this, there is changing clinical evidence regarding practical utilization of the various preparations, as these will have evolved over the time of the establishment of the RAAC.

As new products and data become available, and the patient profile shifts, the service has to be reviewed and adapted to ensure that an efficient, viable, and patientcentered service is maintained.

\section{Recommendations and conclusions}

Reflecting on the development and history of the GSTT RAAC, the authors have identified several key recommendations that underpin the delivery a successful anemia service:

- run a pilot to direct the development of the service and to demonstrate the viability and benefits of the clinic, in order to gain internal support

- provide an easy-access, comprehensive service that not only diagnoses and treats anemia but also investigates the underlying cause in unknown cases

- establish well-defined patient pathways and treatment protocols to deliver an efficient and simple service

- carefully select the IV iron: these are not equivalent, and the choice of product can have an impact on a wide range of service factors, not just cost

- regularly review the service and choice of first-line IV iron to ensure continued provision of a patient-centered service.

To conclude, the GSTT RAAC is a popular, high-demand service, working across multiple therapeutic areas, which both benefits patients and helps to improve the efficiency and quality of health-care provision. This success is dependent on careful design of the service and treatment protocols. This service model is well suited to meet the demands of the current NHS system.

\section{Acknowledgments}

The authors would like to acknowledge the staff who have helped make the RAAC the success it has become. Funding for editorial assistance and publication fees for this article were provided by Vifor Pharma Ltd. Vifor Pharma Ltd, had no input into the editorial content of the paper. Editorial assistance was provided by Aruna Jeans at Pope Woodhead and Associates Ltd.

\section{Disclosure}

Deepti Radia has received honoraria for participating on an advisory panel for Pharmacosmos. Claire Harrison has received unrestricted educational grants from Amgen and Roche. Ibrahim Momoh, Richard Dillon, Yvonne Francis, Laura Cameron, Toni-Lee Fagg, Hannah Overland, and Susan Robinson report no conflicts of interest in this work.

\section{References}

1. Komajda M, Anker SD, Charlesworth A, et al. The impact of new onset anaemia on morbidity and mortality in chronic heart failure: results from COMET. Eur Heart J. 2006;27(12):1440-1446.

2. Nathavitharana RL, Murray JA, D'Sousa N, Sheehan T, Frampton CM, Baker BW. Anaemia is highly prevalent among unselected internal medicine inpatients and is associated with increased mortality, earlier readmission and more prolonged hospital stay: an observational retrospective cohort study. Intern Med J. 2012;42(6):683-691.

3. Schmidt RJ, Dalton CL. Treating anemia of chronic kidney disease in the primary care setting: cardiovascular outcomes and management recommendations. Osteopath Med Prim Care. 2007;1:14.

4. Lefebvre P, Duh MS, Buteau S, Bookhart B, Mody SH. Medical costs of untreated anemia in elderly patients with predialysis chronic kidney disease. J Am Soc Nephrol. 2006;17(12):3497-3502.

5. Barroso F, Allard S, Kahan BC, et al. Prevalence of maternal anaemia and its predictors: a multi-centre study. Eur J Obstet Gynecol Reprod Biol. 2011;159(1):99-105.

6. Goodhand JR, Kamperidis N, Rao A, et al. Prevalence and management of anemia in children, adolescents, and adults with inflammatory bowel disease. Inflamm Bowel Dis. 2012;18(3):513-519.

7. Department of Health. Better blood transfusion: safe and appropriate use of blood. 2007. Available from: http://webarchive.nationalarchives.gov. uk/20120405095111/http://www.dh.gov.uk/prod_consum_dh/groups/ dh_digitalassets/documents/digitalasset/dh_080803.pdf. Accessed November 16, 2011.

8. Department of Health. Tackling hospital waiting: the 18 week patient pathway - an implementation framework and delivery resource pack. 2006. Available from: http://webarchive.nationalarchives. gov.uk/20130107105354/http://www.dh.gov.uk/en/Publicationsandstatistics/Publications/PublicationsPolicyAndGuidance/ DH_4134668. Accessed April 152013.

9. Momoh I, Foster K, Meaney L, et al. Use of erythropoietin (EPO) in adult patients prior to elective major orthopaedics surgery to reduce exposure to allogeneic blood transfusion: a pilot study [abstract]. $\mathrm{Br} J$ Haematol. 2009;145 Suppl 1:81-82.

10. Momoh I. Anaemia and the nurse-led clinic outside renal care. $\mathrm{Br} J$ Card Nurs. 2010;5(9):432-438.

11. British Medical Association, Royal Pharmaceutical Society of Great Britain. British National Formulary (BNF), 62nd ed. London: Pharmaceutical Press; 2011.

12. Electronic Medicines Compendium. Venofer (iron sucrose) - summary of product characteristics. 2011. Available from: http://www.medicines. org.uk/EMC/medicine/24168/SPC/Venofer+(iron+sucrose). Accessed November 16, 2011. 
13. Electronic Medicines Compendium. Cosmofer - summary of product characteristics. 2012. Available from: http://www.medicines.org.uk/ EMC/medicine/14139/SPC/CosmoFer. Accessed April 15, 2013.

14. Electronic Medicines Compendium. Ferinject - summary of product characteristics. http://www.medicines.org.uk/EMC/medicine/24167/ SPC/Ferinject+ferric+carboxymaltose. 2013. Accessed April 15, 2013.

15. Electronic Medicines Compendium. Monofer $100 \mathrm{mg} / \mathrm{mL}$ for injection/ infusion - summary of product characteristics. http://www.medicines. org.uk/EMC/medicine/23669/SPC/Monofer+100mg+ml+solution+for+ injection+infusion. 2013. Accessed April 15, 2013.
16. Dillon R, Momoh I, Francis Y, Cameron L, Harrison C, Radia D. Comparative efficacy of three forms of parenteral iron. J Blood Trans. 2012;2012:473514

17. National Health Service Improvement [homepage on the Internet]. Available from: http://www.improvement.nhs.uk/qipp. Accessed November 16, 2011.

18. NHS Institute for Innovation and Improvement. Better care, better value indicators (incorporating opportunity locator). Available from: http://www.productivity.nhs.uk/Indicator/608/For/National/And/25th/ Percentile. Accessed November 16, 2011.

\section{Publish your work in this journal}

Risk Management and Healthcare Policy is an international, peerreviewed, open access journal focusing on all aspects of public health, policy, and preventative measures to promote good health and improve morbidity and mortality in the population. The journal welcomes submitted papers covering original research, basic science, clinical \& epidemio- logical studies, reviews and evaluations, guidelines, expert opinion and commentary, case reports and extended reports. The manuscript management system is completely online and includes a very quick and fair peerreview system, which is all easy to use. Visit http://www.dovepress.com/ testimonials.php to read real quotes from published authors. 